\title{
An Investigation into Barriers of Technology Transfer in the Construction Industry in Iran and Malaysia
}

\author{
Byung Gyoo Kang1* ${ }^{*}$ Mehrdad Arefi², Boon Hoe Goh ${ }^{2}$, Myung Kyu Song2 \\ ${ }^{1}$ Department of Civil Engineering, Xian Jiaotong-Liverpool University, Suzhou, China \\ ${ }^{2}$ Department of Civil Engineering, University of Nottingham Malaysia Campus, Jalan Broga, Malaysia \\ Email: "Byung-Gyoo.Kang@xjtlu.edu.cn
}

Received 9 April 2015; accepted 11 July 2015; published 14 July 2015

\begin{abstract}
Technology transfer in the international construction industry is an important source as it helps companies move to better stages of design and construction capabilities. Three main barriers of technology transfer in construction have been identified through literature review-language barrier, cultural barrier and procurement options. The importance of these barriers has been identified through survey in the construction industry in Iran and Malaysia. 102 responses were received. Through SPSS analysis, the impacts of these barriers have been identified. The impact percentages are: language barrier $12.1 \%$, cultural barrier $52.8 \%$ and procurement options $88.3 \%$. Future researches are required in procurement options particularly in developing countries.
\end{abstract}

\section{Keywords}

Technology, Transfer, Construction, Barrier

\section{Introduction}

Technology transfer is an important element of relationship among construction companies, especially in the international construction industry. Further, transfer of technology in construction is a source of creativity that makes the company designs and constructs with new technologies. Then the companies are expected to transform and improve the current stage of technologies to the better stages. The process of technology transfer is based on the value and protection of products. It also includes several specific physical processes, systematic methods and managerial arrangements for functioning of the transformation [1] [2]. However, there are several obstacles to transfer of technology.

The objective of this research is to verify the importance of technology transfer in international construction and investigate the impact of three main barriers of technology transfer in the Malaysia construction industry and the Iranian construction industry. The three main barriers identified through literature review are: language barrier, cultural barrier and procurement options.

\footnotetext{
"Corresponding author.
}

How to cite this paper: Kang, B.G., Arefi, M., Goh, B.H. and Song, M.K. (2015) An Investigation into Barriers of Technology Transfer in the Construction Industry in Iran and Malaysia. Open Journal of Social Sciences, 3, 85-91. 


\section{Literature Review}

Kumaraswamy and Shrestha [3] explain that the two enablers are associated to technology transfer-transferor (foreigner) and transferee (host). The transferor's elements comprise four sub-factors, (a) willingness to transfer technology, (b) level of experience, (c) cultural traits and (d) knowledge base. On the other hand, the elements of transferee are (a) intent to learn technology, (b) level of experience, (c) cultural traits and (d) knowledge base. In construction, many researchers have stated that technology transfer in construction is a broadly important influential source of creativity. This helps construction companies to be equipped with new technologies that can properly transform and enhance present technologies to better stages of performance. Typical technology transfer barriers in construction are [4]-[6]: lack of time, organizational culture, capacities of individual (e.g. training skills), lack of clear policy, national/ethnic culture differences, attitudes of individuals (e.g. reluctance), lack of clear agreements, lack of clear procedures, lack of funding provisions, language and procurement. Through intensive and extensive literature review three main barriers of technology transfer have been identified-language barriers [7] [8], cultural barriers [9] [10] and barriers in relation to procurement [10]-[12]. These barriers have been investigated in depth in Malaysia and Iran construction.

\subsection{Language Barriers}

The language barrier has been existed for many years in different sectors in many countries. In the construction industry, employers expect foreign labour to fulfil important needs of construction works due to the lack of local work force. Language barriers make additional complications and misunderstanding in the work place. Workers might pretend that they understand what is being said, but actually they do not fully understand what is being said. This situation can endanger some jobs. All language barriers may not have such direct consequences, but it can affect lack of productivity and lack of trust between the employer and workers which could be avoided if communication is clear. Trajkovski and Loosemore [8] found out that workers whose mother tongue was not English at work place have contributed towards higher accident rates in the construction industry in Australia. Further these foreign workers could not fully understand the instructions and guidelines. Bust et al. [7] discovered that in UK and USA, the language barriers occur among foreign workers in the construction industry. Foreign construction workers faced higher injury risks. They had less training on safety and health as they were not able to communicate in English.

\subsection{Cultural Barriers}

Another main issue of technology transfer which has been existed for long time is cultural differences. The importance of cultural differences is more critical for companies operating in international markets or having employees from different cultures. Ankrah and Proverbs [10] argue that these ideas become more critical in construction because of internationalisation of procurement, the nature of contracting, partnering and joint venture in the industry. In construction, the growth of strategic alliances leads to higher significance of cultural differences because of the interaction of people from different cultures [9]. Some of the common cultural differences and misunderstandings are: Body Language, Personal Appearance, Roles and Status, Personal Space, Religion.

\subsection{Barriers in Relation to Procurements Options}

Four principal procurement options in construction are discussed here. These are design-bid-build, design-build, public private partnership/private finance initiative (PPP?PFI) and partnering.

\subsubsection{Barriers in Relation to Design/Bid/Build}

Design-bid-build has been one of the principal methods of delivery systems for the past few decades. Design bid build separates the design and construction duties. Many owners of the projects have faced diversity of disappointments using this system. The barriers of this procurement method to technology transfer are:

- In Design-bid-build all the design procedure must be completed before tendering stage, leading to longer process duration.

- Technological and programmatic obsolescence can put the owner in difficulty of transferring programmatic and technological changes. 
- Design-bid-build creates more adversarial relationships between the projects participants (designer, owner and contractor) rather than team work and cooperation.

- As the owner is responsible for design, issues related to design change and construability can arise easily.

\subsubsection{Barriers in Relation to Design/Build}

In the last half of the 20th century, the interest in non-traditional construction procurement method grew as clients demanded quicker delivery times and earlier knowledge of construction costs. One of the most popular alternatives to design bid build is design build project delivery method. Combination of both design and construction leads to fast track of projects. However there are some legal problems in using this procurement method, consequently in technology transfer. These are:

- In design/build the clients have less input in proposed design since both the designer and the contractor belong to the same company or consortium.

- Licensing or procurement laws or regulations might affect design/build as it might be limited or restricted to use this procurement method.

- Selection of this process is considered as a complicated and time consuming method in public contracts. This is due to precise procedures and requirements of public contract to bring fair conditions and open competitions.

\subsubsection{Barriers in Relation to Public Private Partnership/Private Finance Initiative}

Public private partnership/private finance Initiative (PPP/PFI) has been contributed to the improvement of infrastructure projects and public services. In PPP/PFI delivery methods, the contractor not only design and build but also finance and operate the public facilities for a concession period. The barriers of this procurement method to technology transfer are:

- The cost of finance is quite high, which can be a burden to private companies.

- The government has explicit and implicit contingent liabilities that may arise due to loan guarantees provided to lenders and default of a private entity on non-guaranteed loans.

- The costs of tendering in PPP/PFI projects are very high.

- Contracts are brought about through complicated negotiations.

- There are variety problems between the private sector and public sector related to different kinds of decision making, accountability and operations.

\subsubsection{Barriers in Relation to Partnering}

There has been a remarkable development in construction industry by using various partnering models since late 1980 's. This has been considered as a significant principal management strategy to develop organizational relations and project performance. Partnering has contributed to the effect to increase satisfaction and mutual benefits to client, consultants and contractors [12]. However, partnering might not be a solution for all issues encountered in the construction process. Moreover the barriers of partnering in respect to technology transfer are:

- Misunderstanding of Partnering Concept: The main thing, while doing the partnering process, is to understand the process, if not this can come out as a critical issue.

- Relationship problems: The main target of partnering is to motivate the participants to change their competitive attitudes to more cooperative and more team-oriented ones. The attitude of competitiveness in a business relationship may prohibit a good relationship between the contract partners.

- Distrust: Trust is an essential element in a business relationship, but is very difficult to create. Without the key element of trust, it is almost impossible to create a win-win situation between the two parties.

- Failure of risk sharing: A successful partnering can be easily threatened by failure of risk sharing. The main issue occurs when the participants of the project face problems to distribute the risk of the partnering process equally.

\section{Findings of the Survey}

The total number of 102 from 300 questionnaires was returned, making the response rate $33 \%$. To increase the response rate, the questionnaires were distributed manually and collected later manually. The participants of the 
survey include architects, engineering consultants, quantity surveyors, contractors and construction managers as shown in Table 1. SPSS (Statistical Package for Social Sciences) has been used for the analysis of data.

\subsection{Reliability Test}

Reliability tests in the independent variables and dependant variables are conducted. Cronbach's Alpha was calculated. To have the reliable variables, Cronbach's Alpha coefficient needs to reach 0.7 for a reliable internal consistency. As it shown in Table 2, the Cronbach's Alpha value is higher than 0.7 , and in case of culture statistics, as the number of items is below six, Cronbach's Alpha value 0.686 is acceptable.

As can be seen from Table 3, only less than 10\% of engineers from Iran and Malaysia consider that technology transfer in international construction is minor issues. The others consider it as average issues (48.9\%) or serious issues $(41.5 \%)$.

\subsection{Statistical Analysis}

Three hypotheses have been developed in relation to barriers to technology transfer in construction projects. These hypotheses have been evaluated from the analysis of the survey outcomes. Both null and alternative hypothesis are considered.

Hypothesis 1:

$H_{a 1}$ : There is a significant relation between language barriers and technology transfer in construction projects.

$H_{o 1}$ : There is no significant relation between language barriers and technology transfer in construction projects.

After doing a regression test, as it shown in Table 4 and Table 5, p-value is under 0.05 and the null hypothe-

Table 1. Response rate.

\begin{tabular}{ccc}
\hline & Responses & Percentage \\
\hline Engineering consultants & 58 & $57 \%$ \\
Contractors & 17 & $17 \%$ \\
Construction managers & 12 & $12 \%$ \\
Architects & 10 & $10 \%$ \\
Quantity surveyors & 5 & $5 \%$ \\
Total & 102 & $100 \%$ \\
\hline
\end{tabular}

Table 2. Reliability tests.

\begin{tabular}{ccc}
\hline Variables & Cronbach's Alpha & Number of Items \\
\hline Language Statistics & 0.720 & 2 \\
Culture Statistics & 0.686 & 5 \\
Procurement Statistics & 0.818 & 12 \\
Technology Transfer Barriers Statistics & 0.773 & 2 \\
\hline
\end{tabular}

Table 3. Seriousness of technology transfer in international construction.

\begin{tabular}{ccccc}
\hline & \multicolumn{4}{c}{ From Experience, Technology Transfer in International Construction Are: } \\
\hline Minor Issues & Average Issues & Serious Issues & Total \\
\hline Iranians & $6(14.6 \%)$ & $19(46.3 \%)$ & $16(39 \%)$ & 41 \\
Malaysians & $3(5.7 \%)$ & $27(50.9 \%)$ & $23(43.4 \%)$ & 53 \\
& $9(9.6 \%)$ & $46(48.9 \%)$ & $39(41.5 \%)$ & 94 \\
\hline
\end{tabular}


sis is rejected and the alternative hypothesis in accepted. The R-square is 0.121 so it has 12.1 percent impact as a barrier in construction projects in technology transfer.

Hypothesis 2

$H_{a 2}$ : There is a significant relation between cultural barriers and technology transfer in construction projects.

$H_{o 2}$ : There is no significant relation between cultural barriers and technology transfer in construction projects.

As can be observed from Table 6 and Table 7, the p-value is below 0.05 so we can accept the alternative hypothesis. The impact of cultural barriers as independent variable is 52.8 percent on technology transfer in construction.

Hypothesis 3

$H_{a 3}$ : There is a significant relation between procurement option barriers and technology transfer in construction projects.

$H_{o 3}$ : There is no significant relation between procurement option barriers and technology transfer in construction projects.

According to Table 8 and Table 9, p-value is below 0.05 so for this hypothesis, the alternative hypothesis is acceptable. It can be deduct from Tables 4-9 the R-square for this test is 0.883 , so procurement options have the strongest impact on technology transfer barrier with 88.3 percent impact.

\section{Conclusion}

Through this research, the importance of technology transfer in international construction has been verified.

Table 4. Model summary for Hypothesis 1.

\begin{tabular}{|c|c|c|c|c|c|c|c|c|}
\hline \multirow[b]{2}{*}{ Model } & \multirow[b]{2}{*}{$\mathrm{R}$} & \multirow[b]{2}{*}{ R Square } & \multirow{2}{*}{$\begin{array}{l}\text { Adjusted R } \\
\text { Square }\end{array}$} & \multicolumn{5}{|c|}{ Change Statistics } \\
\hline & & & & $\begin{array}{l}\text { R Square } \\
\text { Change }\end{array}$ & F Change & df1 & $\mathrm{df} 2$ & Sig. F Change \\
\hline 1 & $0.348^{\mathrm{a}}$ & 0.121 & 0.103 & 0.121 & 6.808 & 2 & 99 & 0.002 \\
\hline
\end{tabular}

Table 5. ANOVA ${ }^{\mathrm{a}}$ for Hypothesis 1.

\begin{tabular}{ccccc}
\hline Model & Sum of Squares & df & Mean Square & F \\
\hline Regression & 3.491 & 2 & 1.745 & 0.808 \\
Residual & 25.382 & 99 & 0.256 \\
Total & 28.873 & 101 & & $0.002^{\mathrm{b}}$ \\
\hline
\end{tabular}

${ }^{\mathrm{a}}$ Dependent Variable: Tech_transfer_barrier. ${ }^{\mathrm{b}}$ Predictors: (Constant), Foreign supervisor faces language problems, Communication in multi-cultural construction sites is made even more complicated.

Table 6. Model summary for Hypothesis 2.

\begin{tabular}{|c|c|c|c|c|c|c|c|c|}
\hline \multirow[b]{2}{*}{ Model } & \multirow[b]{2}{*}{$\mathrm{R}$} & \multirow[b]{2}{*}{ R Square } & \multirow{2}{*}{$\begin{array}{c}\text { Adjusted R } \\
\text { Square }\end{array}$} & \multicolumn{5}{|c|}{ Change Statistics } \\
\hline & & & & $\begin{array}{l}\text { R Square } \\
\text { Change }\end{array}$ & F Change & df1 & $\mathrm{df} 2$ & Sig. F Change \\
\hline 1 & $0.727^{\mathrm{a}}$ & 0.528 & 0.503 & 0.528 & 21.473 & 5 & 96 & 0.000 \\
\hline
\end{tabular}

Table 7. ANOVA ${ }^{\text {a }}$ for Hypothesis 2.

\begin{tabular}{ccccc}
\hline Model & Sum of Squares & df & Mean Square & S \\
\hline Regression & 15.243 & 5 & 3.049 & 21.473 \\
Residual & 13.630 & 96 & 0.142 \\
Total & 28.873 & 101 & & $0.000^{\mathrm{b}}$ \\
\hline
\end{tabular}

${ }^{\mathrm{a}}$ Dependent Variable: Tech transfer barrier. ${ }^{\mathrm{b}}$ Predictors: (Constant), Lack of continuous, open and honest communication, Unfair sharing of risks or rewards among the client and the project participants, Understanding the culture of staff from different countries, Cultural differences for companies operating in international markets, is critical, Unsolved arguments. 
Table 8. Model summary for Hypothesis 3.

\begin{tabular}{|c|c|c|c|c|c|c|c|c|}
\hline \multirow{2}{*}{ Model } & \multirow{2}{*}{$\mathrm{R}$} & \multirow{2}{*}{ R Square } & \multirow{2}{*}{$\begin{array}{c}\text { Adjusted R } \\
\text { Square }\end{array}$} & \multicolumn{5}{|c|}{ Change Statistics } \\
\hline & & & & $\begin{array}{l}\text { R Square } \\
\text { Change }\end{array}$ & F Change & df1 & df2 & Sig. F Change \\
\hline 1 & $0.940^{\mathrm{a}}$ & 0.883 & 0.867 & 0.883 & 54.645 & 12 & 87 & 0.000 \\
\hline
\end{tabular}

Table 9. ANOVA ${ }^{\text {a }}$ for Hypothesis 3.

\begin{tabular}{ccccc}
\hline Model & Sum of Squares & df & Mean Square & F \\
\hline Regression & 25.171 & 12 & 2.098 & 54.645 \\
Residual & 3.339 & 87 & 0.038 & $0.000^{\mathrm{b}}$ \\
Total & 28.510 & 99 & &
\end{tabular}

${ }^{\mathrm{a}}$ Dependent Variable: Tech_transfer_barrier. ${ }^{\mathrm{b}}$ Predictors: (Constant), High cost of tendering in PPP/PFI projects, Procurement laws and regulations negatively effect in design/build contract, Changes in design during construction, Local partners (companies) have no input on design in design/build contract, Partners failed to build a trust relationship, Unnecessary interference from government for PPP/PFI projects, Partners failed to share information, PPP/PFI contracts create/required complicated negotiations, Long process in design procedure in design-bid-build, Too long term concession period for PPP/PFI projects, Partners' lack of win-win attitude, Misunderstanding/conflict due to laws and regulations of local government

Further three main barriers of technology transfer have been identified and analysed through questionnaire survey. These are language barrier, cultural barrier and procurement options. Positive relations have been found between "technology transfer in international construction" and all of these three barriers. The impact percentages are language barrier $12.1 \%$, cultural barrier $52.8 \%$ and procurement options $88.3 \%$. In most international construction projects, the professional workers have sufficient English skills as international language. Possibly this is the cause of low impact from language barrier. To overcome cultural barrier, diverse cultural programmes need to be considered in international construction environments. Procurement options particularly with respect to PPP/PFI should be studied in depth to implement efficient and effective technology transfer. The outcomes of this research will make a good contribution in respect to technology transfer issues in construction especially for developing countries. For future research, the investigation can be extended to other countries in Asia and/or Africa to understand differences and make comparisons between regions and countries.

\section{References}

[1] Putranto, K., Stewart, D. and Moore, G. (2003) International Technology Transfer and Distribution. Journal of Technology in Society, 25, 143-153.

[2] Wie, T.K. (2003) The Major Channels of International Technology Transfer to Indonesia. The Asia Pacific Economy, 10, 2214-2236.

[3] Kumaraswamy, M.M. and Shrestha, G.B. (2002) Targeting Technology Exchange for Faster Organizational and Industry Development. Building Research \& Information, 30, 3183-3195. http://dx.doi.org/10.1080/09613210110115216

[4] Sexton, M.G., Barrett, P. and Aouad, G. (1999) Diffusion mechanisms for construction research and innovation into small to medium sized construction firms, CRISP-99/7, London.

[5] Nonaka, I. and Takeuchi, H. (1995) The Knowledge-Creating Company: How Japanese Companies Create Dynamics of Innovation. Oxford University Press.

[6] Kogut, B. and Zander, U. (1992) Knowledge of the Firm Combinative Capabilities, and the Replication of Technology. Organization Science, 3, 383-397. http://dx.doi.org/10.1287/orsc.3.3.383

[7] Bust, P.D., Gibb, A.G.F. and Pink, S. (2008) Managing Construction Health and Safety: Migrant Workers and Communicating Safety Messages. Safety Science, 46, 585-602.

[8] Trajkovski, S. and Loosemore, M. (2006) Safety Implications of Low-English Proficiency among Migrant Construction Site Operatives. International Journal of Project Management, 24, 446-452.

[9] Shore B. and Cross, B.J. (2005) Exploring the Role of National Culture in the Management of Large-Scale International Science Projects. International Journal of Project Management, 23, 55-64.

[10] Ankrah, N.A. and Proverbs, D. (2004) Treading the Softer Areas of Construction Management: A Critical Review of Culture. Association of Researchers in Construction Management, 1, 3551-3558. 
[11] Larson, E. and Drexler, J.A. (1997) Barriers to Project Partnering: Report for the Firing Line. Project Management Journal, 28, 146-152.

[12] Loraine, R.K. (1994) Project Specific Partnering. Engineering, Construction and Architectural Management, 1, 15-16. http://dx.doi.org/10.1108/eb020989 